\title{
ANALISIS HASIL PRAKTIKUM PEMERIKSAAN KADAR HEMOGLOBIN DENGAN INDEKS MASSA TUBUH PADA MAHASISWA
}

\author{
Analysis Of Praktikum Results Test Hemoglobin Level \\ With Body Mass Index In Students \\ Danik Riawati ${ }^{1}$, Ajeng Novita Sari $^{2}$, Syarifah ${ }^{3}$ \\ Akademi Teknologi Bank Darah Surakarta ${ }^{1}$, Politeknik Santo Paulus Surakarta ${ }^{2}$, \\ Akademi Teknologi Bank Darah Surakarta ${ }^{3}$ \\ (riawatidanik81@gmail.com)
}

\begin{abstract}
ABSTRAK
Latar belakang: Pemeriksaan kadar hemoglobin merupakan cara untuk mengetahui apakah seseorang mengalami anemia maupaun tidak. Mahasiswa diharapkan mampu mengembangkan pengetahuan dan ketrampilan dengan cara memahami dan mengimplementasikan pemeriksaan hemoglobin pada saat praktikum penyadapan darah.

Tujuan: Untuk mengetahui hubungan antara hasil praktikum pemeriksaan kadar hemoglobin dengan Indeks Massa Tubuh pada mahasiswa.

Metode : Penelitian ini merupakan penelitian observasional analitik dengan pendekatan cross sectional. Populasi penelitian ini adalah mahasiswa semester 3B di AKBARA yang pratikum penyadapan darah. Subyek penelitian ini adalah seluruh mahasiswa semester 3B yang praktikum penyadapan darah pada bulan Desember 2019 sebanyak 33 responden. Metode pengumpulan data menggunakan data primer dan data sekunder. Analisa data menggunakan analisa univariat yang disajikan dalam bentuk tabel distribusi frekuensi dan analisis bivariat menggunakan uji korelasi kendall's tau-b.

Hasil: Karakteristik responden sebagian besar berjenis kelamin perempuan dengan umur $>19$ tahun 12 responden $(36,4 \%)$ dan perempuan yang tidak mengalami anemia sebanyak 15 responden $(45,5 \%)$ serta perempuan sebagian besar memiliki IMT 18,5-25 sebanyak 16 responden (48,5\%), responden perempuan yang memiliki IMT 18,5-25 mengalami anemia sebanyak 12 responden $(40 \%)$.

Simpulan: Tidak ada hubungan antara hasil praktikum pemeriksaan kadar hemoglobin dengan Indeks Massa Tubuh pada mahasiswa prodi DIII Teknologi Bank Darah Surakarta.
\end{abstract}

Kata kunci: Kadar Haemoglobin, Indeks Massa Tubuh, Mahasiswa

\section{ABSTRACT}

Background: The hemoglobin level test is a way to determine if a person is not suffering from anemia. Students are expected to develop knowledge and skills by understanding and implementing hemoglobin examination at the time of practicum of blood tapping. 
The Aim: To know the relationship between the practicum results of examination of the hemoglobin level with the body mass index in the student .

Method: This research is an analytical observational research with a cross sectional approach. The population of this study is a $3 B$ semester student in AKBARA which pratikum blood tapping. The subject of this study was all $3 B$ semester students who had a blood tapping practicum in December 2019 as many as 33 respondents. Data collection methods use primary data and secondary data. Analysis of data using univariate analysis presented in the form of frequency distribution tables and bivariate analysis using the correlation test Kendall's tau$B$.

Result: Characteristics of respondents of most female genders with age > 19 years 12 respondents (36.4\%) and women who do not suffer from anemia as many as 15 respondents (45.5\%) And women mostly have BMI 18.5-25 as many as 16 respondents (48.5\%), female respondents who had a IMT 18.5-25 had anemia 12 respondents $(40 \%)$.

Conclusion: There is no link between the results of the practicum of examining the hemoglobin level with the body mass index in the student Prodi DIII technology of Surakarta.

Key words: Haemoglobin levels, body mass index, students

\section{PENDAHULUAN}

Hasil Riskesdas tahun 2018 mengambarkan bahwa prevalensi penyakit tidak menular menurut diagnosis dokter seperti: kanker mencapai 1,8 permil; stroke pada penduduk usia $>15$ tahun mencapai 10,9 permil dan usia 55-64 sebanyak 6,3\%; diabetes melitus pada penduduk usia $>15$ tahun sebesar $2 \%$; hipertensi pada penduduk usia $>18$ tahun sebesar 34,1\%. Proporsi berat badan lebih dan obesitas pada orang dewasa usia $>18$ tahun yaitu BB lebih mencapai 13,6\% dan obesitas mencapai 21,8\% (Kemesnkes RI, 2018). Berdasarkan hal tersebut didapatkan salah satu masalah yaitu pada penduduk usia $>18$ tahun mempunyai BB lebih dan obesitas yang masih cukup tinggi. Ukuran untuk penilaian kategori BB seseorang dengan menimbang berat badan dan mengukur tinggi badan. Berdasarkan $\mathrm{BB}$ dan TB maka dapat dihiting indeks massa tubuh seseorang. Indeks Massa tubuh (IMT) merupakan ukuran yang menyaktakan bahwa adanya kekurangan atau kelebihan. Nilai batas ambang $<18,5 \mathrm{Kg} / \mathrm{m}^{2}$ kurus, normal 18,5$25 \mathrm{Kg} / \mathrm{m}^{2}$, obesitas $>25 \mathrm{Kg} / \mathrm{m}^{2}$ (Kemenkes RI, 2014). Misalnya pada masa remaja mengalami perubahan gaya hidup dan kebiasaan makan yang salah dapat dapat mempengaruhi jumlah konsumsi makanan dan zat gizi. Contohnya apabila kekurangan zat besi maka akan terjadi anemia. Kebutuhan zat besi akan meningkat pada saat kematangan seksual baik pada remaja laki-laki maupun perempuan (BKKBN, 2012). Kebutuhan zat besi kurang maka apabila di cek laboratorium terdapat penurunan kadar hemoglobinnya, karena anemia didefinisikan sebagai suatu kondisi dimana terdapat kekurangan sel darah merah atau hemoglobin (Kemenkes RI, 2013). 
Hemoglobin merupakan suatu komponen yang mepunyai fungsi sebagai alat transportasi $\left(\mathrm{O}_{2}\right)$ dan karbondioksida $\left(\mathrm{CO}_{2}\right)$. Beberapa faktor yang mempengaruhi kadar HB seperti orang yang tinggal di dataran tinggi, asupan cairan yang berlebihan, nilai HB bayi tinggi, saat hamil, mengkonsusi obat dan olah raga ekstrim (Kemenkes RI, 2011). Hasil pemeriksaan nilai kadar hemoglobin normal menurut WHO dalam Permenkes RI tahun 2014 bahwa laki-laki >13gr/dl, perempuan $>12 \mathrm{gr} / \mathrm{dl}$ dan ibu hail $>11 \mathrm{gr} / \mathrm{dl}$ (Permenkes RI, 2014). Berdasarkan hal tersebut berarti nilai IMT dan kadar $\mathrm{Hb}$ tergantung cakupan asupan makanan yang dikonsumsi. Penelitian terdahulu yang relevan Sukarno J.K, Marunduh. S.R dan Pangemanan D.H.C tahun 2016 di dapatkan bahwa terdapat hubungan antara indek masa tubuh dengan kadar haemoglobin remaja di Bolangitang Barat Kabupaten Bolaang Mongondow Utara. Penelitian lain yang sejenis yaitu menurut Azizah S tahun 2015 menyimpulkan bahwa terdapat pengaruh antara obesitas terhadap kadar hemoglobin pada remaja perempuan dengan kekuatan korelasi sedang.

Studi pendahuluan yang dilakukan pada bulan November didapatkan ada beberapa mahasiswa yang mengalami anemia. Berdasarkan hal diatas maka penulis tertarik menggambil judul penelitian " Analisis Hasil Praktikum Pemeriksaan Kadar Hemoglobin Dengan Indeks Massa Tubuh pada mahasiswa prodi DIII Teknologi Bank Darah Surakarta ". tujuan penelitian ini adalah untuk menegetahui hubungan antara hasil praktikum pemeriksaan kadar hemoglobin dengan Indeks Massa Tubuh pada mahasiswa prodi DIII Teknologi Bank Darah Surakarta

\section{METODE PENELITIAN}

Penelitian ini merupakan penelitian observasional analitik dengan pendekatan cross sectional. Populasi penelitian ini adalah mahasiswa semester 3B di AKBARA yang pratikum penyadapan darah. Subyek penelitian ini adalah seluruh mahasiswa semester 3B yang praktikum penyadapan darah pada bulan Desember 2019 sebanyak 33 responden. Metode pengumpulan data menggunakan data primer dan data sekunder. Analisa data menggunakan analisa univariat yang disajikan dalam bentuk tabel distribusi frekuensi dan analisis bivariat menggunakan uji korelasi kendall's tau-b.

\section{HASIL DAN PEMBAHASAN}

\section{Hasil}

Tabel 1 Distribusi Frekuensi Berdasarkan Umur Dan Jenis Kelamin Responden

\begin{tabular}{ccccccc}
\hline \multirow{2}{*}{ Umur } & \multicolumn{2}{c}{ Perempuan } & \multicolumn{3}{c}{ Laki-laki } & \multicolumn{2}{c}{ Jumlah } \\
& $\mathrm{f}$ & $\%$ & $\mathrm{f}$ & $\%$ & $\mathrm{f}$ & $\%$ \\
\hline$\leq 19 \mathrm{Th}$ & 9 & 27,3 & 3 & 9,1 & 12 & 36,4 \\
$>19 \mathrm{Th}$ & 12 & 36,4 & 9 & 27,3 & 21 & 63,6 \\
Jumlah & 21 & 63,6 & 12 & 36,4 & 33 & 100 \\
\hline \multicolumn{2}{l}{ Sumber: data primer 2019}
\end{tabular}


Berdasarkan tabel 1 didapatkan bahwa sebagian besar berumur $>19$ tahun dan berjenis kelain perempuan yaitu 12 responden $(36,4 \%)$ dan laki-laki 9 responden $(27,3 \%)$.

Tabel 2 Distribusi Frekuensi Berdasarkan Kejadian Anemia

\begin{tabular}{lcccccc}
\hline \multirow{2}{*}{ Jenis Kelamin } & Anemia & \multicolumn{2}{c}{ Tidak anemia } & \multicolumn{2}{c}{ Jumlah } \\
& $\mathrm{f}$ & $\%$ & $\mathrm{f}$ & $\%$ & $\mathrm{f}$ & $\%$ \\
\hline Perempuan & 6 & 18,2 & 15 & 45,5 & 21 & 63,6 \\
Laki-laki & 2 & 6,1 & 10 & 30,3 & 12 & 36,4 \\
Jumlah & 8 & 24,2 & 25 & 75,8 & 33 & 100 \\
\hline
\end{tabular}

Sumber: data primer 2019

Berdasarkan tabel 2 didapatkan bahwa sebagian besar perempuan yang tidak mengalami anemia sebanyak 15 responden $(45,5 \%)$, dan laki-laki yang tidak mengalami anemia sebanyak 10 responden $(30,3 \%)$.

Tabel 3 Distribusi Frekuensi Berdasarkan Indeks Massa Tubuh (IMT)

\begin{tabular}{lcccccc}
\hline & \multicolumn{4}{c}{ Jenis Kelamin (JK) } & \multicolumn{2}{c}{ Jumlah } \\
\multicolumn{1}{c}{ IMT } & Perempuan & \multicolumn{2}{c}{ Laki-laki } & f & $\%$ \\
\hline$<18,5$ & 5 & 15,2 & 1 & 3,0 & 6 & 18,2 \\
$18,5-25$ & 16 & 48,5 & 8 & 24,2 & 24 & 72,7 \\
$>25$ & 0 & 0,0 & 3 & 9,1 & 9,1 & 9,1 \\
\hline \multicolumn{1}{c}{ Jumlah } & 21 & 64 & 12 & 36 & 33 & 100 \\
\hline
\end{tabular}

Sumber: data primer 2019

Berdasarkan tabel 3 didapatkan bahwa sebagian besar yang memiliki Indeks Massa Tubuh 18,5-25 yaitu perempuan sebanyak 16 responden (48,5\%) dan lakilaki 8 responden $(24,2 \%)$.

Tabel 4 Distribusi Frekuensi Indeks Massa Tubuh (Imt) Dan Kadar Hemoglobin Berdasarkan Jenis Kelamin

\begin{tabular}{|c|c|c|c|c|c|c|c|}
\hline \multirow{3}{*}{ IMT } & \multirow{3}{*}{ JK } & \multicolumn{4}{|c|}{ Kejadian Anemia } & \multirow{2}{*}{\multicolumn{2}{|c|}{ Jumlah }} \\
\hline & & \multicolumn{2}{|c|}{ Anemia } & \multicolumn{2}{|c|}{ Tidak anemia } & & \\
\hline & & $\mathrm{f}$ & $\%$ & $\mathrm{f}$ & $\%$ & $\mathrm{f}$ & $\%$ \\
\hline \multirow[t]{2}{*}{$<18,5$} & $\mathrm{P}$ & 3 & 9,1 & 2 & 6,1 & 5 & 15,2 \\
\hline & $\mathrm{L}$ & 0 & 0,0 & 1 & 3,0 & 1 & 3,0 \\
\hline \multirow[t]{2}{*}{$18,5-25$} & $\mathrm{P}$ & 12 & 36,4 & 4 & 12,1 & 16 & 48,5 \\
\hline & $\mathrm{L}$ & 3 & 9,1 & 5 & 15,2 & 8 & 24,2 \\
\hline \multirow[t]{2}{*}{$>25$} & $\mathrm{P}$ & 0 & 0,0 & 0 & 0,0 & 0 & 0,0 \\
\hline & $\mathrm{L}$ & 3 & 9,1 & 0 & 0,0 & 3 & 9,1 \\
\hline Jumlah & & 21 & 63,6 & 12 & 36,4 & 33 & 100 \\
\hline
\end{tabular}

Berdasarkan tabel 4 didapatkan bahwa sebagian besar responden memiliki Indeks Massa Tubuh (IMT) 18,5-25 yaitu perempuan mengalami anemia 
sebanyak 12 responden (40\%) dan sebagian besar laki-laki tidak mengalami anemia sebanyak 5 responden $(16,7 \%)$.

Tabel 5 Analisis Bivariat uji korelasi kendall's tau-b Hasil Praktikum Pemeriksaan Kadar Hemoglobin Dengan Indeks Massa Tubuh

\begin{tabular}{lllll}
\hline Correlations & & & & \\
\hline & & & Hb & IMT \\
\hline Kendall's tau_b & Hb & Correlation Coefficient & 1.000 & .155 \\
& & Sig. (2-tailed) &. & .222 \\
& & N & 33 & 33 \\
& IMT & Correlation Coefficient & .155 & 1.000 \\
& & Sig. (2-tailed) & .222 &. \\
& & N & 33 & 33 \\
\hline
\end{tabular}

Berdasarkan tabel 5 didapatkan koefisien korelasi kendall's tau $b$ sebesar sebesar 0,155, karena nilai mendekati 0 maka hubungan antara kadar Hb dengan IMT adalah lemah. Kesimpulanya dari hasil analisa bivariat bahwa nilai signifikansi sebesar 0,222 >0,05 maka hipotesis nol diterima, sehingga tidak ada hubungan antara hasil praktikum pemeriksaan kadar hemoglobin dengan Indeks Massa Tubuh pada mahasiswa prodi DIII Teknologi Bank Darah Surakarta.

\section{Pembahasan}

Berdasarkan tabel 1 didapatkan bahwa sebagian besar berumur $>19$ tahun dan berjenis kelain perempuan yaitu 12 responden $(36,4 \%)$ dan laki-laki 9 responden $(27,3 \%)$. Hal ini sesuai dengan teori bahwa James-Traore (2001:12) dalam buku Imron A tahun 2012 membedakan remaja menurut perkembangan fisik yaitu remaja awal usia 10-14 tahun, remaja pertengahan usia 15-19 tahun dan dewasa muda 20-24 tahun. Berdasarkan usia responden dan dilihat dari pendidikannya maka responden termasuk kategorik remaja pertengahan dan dewasa muda.

Berdasarkan tabel 2 didapatkn bahwa sebagian besar perempuan yang tidak mengalami anemia sebnyak 15 responden $(45,5 \%)$, dan laki-laki yang tidak mengalami anemia sebanyak 10 responden $(30,3 \%)$. Hal ini sesuai dengan teori bahwa kebutuhan zat besi akan meningkat pada saat kematangan seksual baik pada remaja laki-laki maupun perempuan (BKKBN, 2012). Pada masa ini mereka mengalami perubahan gaya hidup dan kebiasaan makan yang salah dapat dapat mempengaruhi jumlah konsumsi makanan dan zat gizi. Adapaun faktor resiko pada penderita anemia defisiensi besi antara lain ibu hamil, remaja putri, status gizi kurang, faktor ekonomi kurang, infeksi kronik dan vegetarian (PBIDI, 2017). hasil penelitian ini ternyata yang berjenis kelamin perempuan sebagian besar tidak mengalami anemia maka terdapat kesenjangan dengan teori yang menyatakan bahwa biasanya perempuan sering mengalami anemia yang disebabkan oleh kandungan zat besi yang kurang, mengalami haid, diet berlebihan, infeksi cacing yang berlangsung lama serta perdarahan (BKKBN, 2009). 
Berdasarkan tabel 3 didapatkan bahwa sebagian besar yang memiliki Indeks Massa Tubuh 18,5-25 yaitu perempuan sebanyak 16 responden $(48,5 \%)$ dan lakilaki 8 responden $(24,2 \%)$.

Hal ini sesuai dengan teori bahwa Indeks Massa Tubuh (IMT) dapat dihitung dengan menggunakan rumus yaitu berat badan dibagi tinggi badan dalam $\mathrm{m}^{2}$. Nilai batas ambang IMT berdasarkan ketentuan WHO. Negara Indonesia memodifikasi nilai batas ambang IMT berdasarkan pengalaman klinis dan penelitian di negara berkembang. Kategori kurus jika IMT<18,5; normal 18,5-25 dan gemuk $>25$ (Kemenkes RI, 2014). hal ini juga didukung oleh penelitian Hanifah L dan Riawati D tahun 2018 yang menyatakan bahwa terdapat hubungan antara status gizi dengan perkembangan anak pada usia 3-5 tahun.

Berdasarkan tabel 4 didapatkan bahwa sebagian besar responden memiliki Indeks Massa Tubuh (IMT) 18,5-25 yaitu perempuan mengalami anemia sebanyak 12 responden (40\%) dan sebagian besar laki-laki tidak mengalami anemia sebanyak 5 responden (16,7\%). Hal ini sesuai dengan teori bahwa faktor resiko pada penderita anemia defisiensi besi antara lain ibu hamil, remaja putri, status gizi kurang, faktor ekonomi kurang, infeksi kronik dan vegetarian dengan nilai rujukan kadar hemoglobin normal menurut WHO yaitu kadar hemoglobin laki-laki $>13 \mathrm{~g} / \mathrm{dl}$, perempuan $>12 \mathrm{~g} / \mathrm{dl}$, dan ibu hamil >11 g/dl (PBIDI, 2017).

Berdasarkan tabel 5 didapatkan koefisien korelasi kendall's tau $b$ sebesar sebesar 0,155, karena nilai mendekati 0 maka hubungan antara kadar Hb dengan IMT adalah lemah. Kesimpulanya dari hasil analisa bivariat bahwa nilai signifikansi sebesar 0,222 > 0,05 maka hipotesis nol diterima, sehingga tidak ada hubungan antara hasil praktikum pemeriksaan kadar hemoglobin dengan Indeks Massa Tubuh pada mahasiswa prodi DIII Teknologi Bank Darah Surakarta. Hal ini sejalan dengan penelitian Handayani S tahun 2017 menyatakan bahwa tidak terdapat hubungan bermakna antara kegemukan dengan responsivitas asuhan zat besi pada remaja puri dengan anemia.

\section{SIMPULAN DAN SARAN}

\section{Simpulan}

Karakteristik responden sebagian besar berjenis kelamin perempuan dengan umur $>19$ tahun 12 responden $(36,4 \%)$ dan perempuan yang tidak mengalami anemia sebanyak 15 responden $(45,5 \%)$ serta perempuan sebagian besar memiliki IMT 18,5-25 sebanyak 16 responden (48,5\%), responden perempuan yang memiliki IMT 18,5-25 mengalami anemia sebanyak 12 responden (40\%). Hasil koefisien korelasi kendall's tau b sebesar sebesar 0,155, maka tidak ada hubungan antara hasil praktikum pemeriksaan kadar hemoglobin dengan Indeks Massa Tubuh pada mahasiswa prodi DIII Teknologi Bank Darah Surakarta. Tidak ada hubungan antara hasil praktikum pemeriksaan kadar hemoglobin dengan Indeks Massa Tubuh pada mahasiswa prodi DIII Teknologi Bank Darah Surakarta

\section{Saran}

Bagi mahasiswa diharapkan lebih memperhatikan kecukupan asuhan gizi supaya kadar hemoglobin normal. 


\section{DAFTAR PUSTAKA}

Azizah S, 2015. Pengaruh Obesitas Terhadap Kadar Hemoglobin Pada Remaja Perempuan. Laporan Skripsi Mahasiswa Fakultas Kedokteran UNS. https://eprints.uns.ac.id/24310/1/G0012211_pendahuluan.pdf. Diakses tanggal 20 Desember 2019, jam 11.00 WIB.

BKKBN, 2012. Materi Pegangan Kader Tentang Bimbingan dan Pembinaan Keluarga Remaja. Jakarta: BKKBN Direktorat Bina Ketahanan Remaja.

Imron A, 2012. Pendidikan Kesehatan Reproduksi Remaja. Jogjakarta: Ar-Ruzz Media.

Handayani S, 2017. Laporan Skripsi Mahasiswa Fakultas Kedokteran UNS. Hubungan Antara Kegemukan dengan Responsivitas Asupan Zat Besi pada Remaja Putri dengan Anemia. https://eprints.uns.ac.id/39831/1/G0014222_pendahuluan.pdf. Diakses tanggal 20 Desember 2019, jam 10.00 WIB.

Hanifah L dan Riawati D tahun 2018. Hubungan Status Gizi Dengan Perkembangan Anak Usia 3-5 tahun di Posyandu Tawangsari Mojosongo Jebres Surakarta. Jurnal Kebidanan Harapan Ibu Pekalongan Vol 4 No .1, Agustus 2018 , ISSN Online 2579-5481 ; ISSN Cetak 2549-2772 ; halaman : 136-140 https://akbidhipekalongan.ac.id/ejournal/index.php/akbidhip/issue/view/9. Diakses tanggal 20 Desember 2019, jam 10.00 WIB, jam : 10.00 WIB.

Kemenkes RI, 2011. Pedoman Interpretasi Data Klinik. Jakarta: Kemenkes RI. http://www.binfar.depkes.go.id/v2/wpcontent/uploads/2014/11/PEDOMAN-INTERPRETASI-DATAKLINIK.pdf. Diakses tanggal 10 Desember 2019, jam : 10.00 WIB.

Kemenkes RI, 2013. Buku Saku Pelayanan Kesehatan Ibu di Farsilitas Kesehatan Dasar dan Rujukan. https://draguscn.com/wpcontent/uploads/2018/02/buku-saku-pelayanan-kesehatan-ibu.pdf. Diakses pada tanggal 20 Desember 2019, jam 09.00 WIB.

Kemenkes RI, 2014. Pedoman Gizi Seimbang. Jakarta: Kemenkes RI.

Kemenkes RI, 2018. Pedoman Pembinaan Krida Bina Perilaku Hidup Bersih dan Sehat (PHBS).

http://promkes.kemkes.go.id/download/dsgq/files99874PHBS.pdf. Diakses pada tanggal 20 Desember 2019, jam 09.00 WIB.

Permenkes, 2014. Peraturan Meteri Kesehatan Republik Indonesia Nomor 5 Tahun 2014 Tentang Panduan Praktik Klinis bagi Dokter di Farsilitas Pelayanan Kesehatan Primer. https://peraturan.bkpm.go.id/jdih/userfiles/batang/Permenkes_5_2014.pdf. Diakses pada tanggal 20 Desember 2019, jam 09.00 WIB.

PBIDI, 2017. Panduan Praktik Klinik Bagi Dokter Di Farsilitas Pelayanan Kesehatan Tingkat Pertama. https://drive.google.com/file/d/1ZMiIq0VIFd33IXmP8vCwctTuZdyX2XS/view. Diakses tanggal 20 Desember 2019, jam 10.00 WIB

Sukarno J.K, Marunduh. S.R dan Pangemanan D.H.C, 2016. Hubungan Indeks Massa Tubuh Dengan Kadar Hemoglobin Pada Remaja di Kecamatan 
Jurnal Kebidanan Indonesia. Vol 11 No 1. Januari 2020 (108 - 115)

Bolangitang Barat Kabupaten Bolang Mongondow Utara. Jurnal Kedokteran Klinik Volume 1 No. 1 Desember 2016 https://ejournal.unsrat.ac.id/index.php/jkk/article/view/14360/13933. Diakses tanggal 20 Desember 2019, jam 10.00 WIB. 